\title{
Seroepidemiology, Spatial Distribution, and Risk Factors of Francisella tularensis in Jordan
}

\author{
Mohammad M. Obaidat, ${ }^{1 *}$ Lile Malania, ${ }^{2}$ Alaa E. Bani Salman, ${ }^{1}$ Ryan J. Arner, ${ }^{3}$ and Amira A. Roess ${ }^{4,5}$ \\ ${ }^{1}$ Department of Veterinary Pathology and Public Health, Faculty of Veterinary Medicine, Jordan University of Science and Technology, Irbid, \\ Jordan; ${ }^{2}$ National Center for Disease Control and Public Health, Tbilisi, Georgia; ${ }^{3}$ Ryan Arner Science Consulting, LLC, Freeport, Pennsylvania; \\ ${ }^{4}$ Department of Global Health, Milken Institute School of Public Health, George Washington University, Washington, District of Columbia; \\ ${ }^{5}$ Department of Global and Community Health, College of Health and Human Services, George Mason University, Fairfax, Virginia
}

\begin{abstract}
There is a paucity of data on Francisella tularensis in the Middle East and North Africa. This is the first countrywide study to determine the seroprevalence, spatial distribution, and risk factors for $F$. tularensis in Jordan. A total of 828 Jordanians were serologically tested for $F$. tularensis by ELISA. These individuals filled out a self-administered questionnaire to collect demographic and risk factor information. Bivariate and multivariate logistic regressions were performed to determine which variables are associated with seropositivity. The overall seroprevalence of $F$. tularensis was $7.7 \%$ (95\% Cl: 6.10-9.75). The bivariate analyses showed that age, region of residence, small ruminant ownership, and practicing horticulture were significantly associated with seropositivity, and these variables were controlled for in the multivariate analysis. The multivariate analysis showed an increased odds of seropositivity among individuals living in northern desert, middle, and northern highland areas, compared with individuals living in the drier southern area, as 7.27 (95\% Cl: 2.49-21.19), 3.79 (95\% Cl: 1.53-9.39), and 3.52 (95\% Cl: 1.45-388.55), respectively. Individuals owning a small ruminant had $1.86(95 \% \mathrm{Cl}: 1.02-3.40)$ greater odds for seropositivity than individuals who do not own a small ruminant. Individuals practicing horticulture had 2.10 (95\% Cl: 1.20-3.66) greater odds for seropositivity than individuals who do not practice horticulture. This is the first study to address the seroprevalence of $F$. tularensis in Jordan and the Middle East. Further research is needed to identify clinical cases of tularemia in Jordan and to determine the circulating $F$. tularensis subspecies.
\end{abstract}

\section{INTRODUCTION}

Francisella tularensis is a Gram-negative intracellular coccobacillus. Two of the four subspecies of $F$. tularensis, namely, tularensis and holarctica, cause disease in humans. ${ }^{1}$ The pathogen survives for months in soil, water, and dead animals but is easily killed by heat and water chlorination. Francisella tularensis has a broad range of hosts including birds, and domestic and wild mammals ${ }^{2}$ and can be transmitted by several species of ticks, flies, and mosquitoes. ${ }^{3,4}$ In addition, F. tularensis can be transmitted by consuming undercooked infected meat (e.g., rabbits), drinking contaminated water, and inhaling contaminated hay, grain, and soil dust. ${ }^{5}$ Following 1-14 days of incubation, the disease, tularemia, can present in six different forms: glandular, ulceroglandular, oculoglandular, oropharyngeal, typhoidal, and pneumonic. ${ }^{5}$

Tularemia has been reported in several countries, mainly in the Northern Hemisphere, such as in the United States, ${ }^{6}$ Europe, ${ }^{2}$ the Republic of Georgia, ${ }^{7}$ Turkey, ${ }^{8}$ Japan, ${ }^{9}$ and China. ${ }^{10}$ Meanwhile, there is a paucity of data on the disease in the Middle East-North Africa region. However, the disease has been reported in Iran. ${ }^{11}$

The lack of the reports about tularemia in different countries might be attributed to the fact that this rare disease presents with a broad spectrum of clinical signs and often goes undiagnosed. For example, a study in Kenya found $3.7 \%$ of febrile illnesses tested positive for $F$. tularensis antibodies, although none of the providers suspected tularemia as a potential diagnosis. ${ }^{12}$ This scenario was also reported in the United States, where more than half of the confirmed tularemia cases were not initially suspected until the incidental isolation of the $F$. tularensis. ${ }^{6}$ This study aimed to

*Address correspondence to Mohammad M. Obaidat, Department of Veterinary Pathology and Public Health, Faculty of Veterinary Medicine, Jordan University of Science and Technology, King Hussain St., Irbid 22110, Jordan. E-mail: mmobaidat@just.edu.jo determine the seroprevalence, spatial distribution, and risk factors for $F$. tularensis in Jordan.

\section{MATERIALS AND METHODS}

Setting and participants. This was a cross-sectional study carried out between November 2015 and May 2016. This study recruited participants from 11 of the 12 governorates in Jordan. Jordan is an upper-middle-income country of 9.7 million people located in the Middle East and Northern Africa. ${ }^{13}$ Participants were Jordanian citizens who accompanied relatives who attended local health centers for general health examinations. From each governorate, two to six health centers were randomly selected from the Ministry of Health center directory for inclusion in the study. Participants were recruited by registered nurses for participation in the study and briefed about the purpose of the study. Blood samples were collected from the participants by registered nurses. Serum was harvested from the samples by centrifugation at $3,000 \mathrm{rpm}$ for 10 minutes and stored at the health centers until they were shipped to the Food Safety and Zoonotic Diseases Laboratory at the Jordan University of Science and Technology (JUST). The harvested sera were stored in aliquots (ca. $200 \mu \mathrm{L}$ each) at $-20^{\circ} \mathrm{C}$ until analyses. All sera were documented in the inventory and labeled properly with a unique identifier that included the governorate, health center name, and the number of the sample. Samples were tested within 4 weeks of storage.

Sample size. There are no data on the seroprevalence of F. tularensis in Jordan; thus, we calculated the largest needed sample size $(n)$ of 384 to detect a seroprevalence rate of $0.5 \pm$ 0.05 . However, sera of 828 participants were tested to increase the power of the analysis.

Laboratory analysis. The serum samples were tested for IgG antibodies to lipopolysaccharides of $F$. tularensis using Serion ELISA classic F. tularensis IgG (Virion $\backslash S e r i o n ~ G m b H$, Würzburg, Germany) in accordance with the manufacturer's 
instructions. The kit showed $96.3 \%$ sensitivity and $96.8 \%$ specificity. ${ }^{14}$ Antibody titers $>15 \mathrm{U} / \mathrm{mL}$ were reported as positive as recommended by the manufacturer. Positive samples were tested by Rose Bengal (Vircell, Granada, Spain) to investigate the possibility of a cross-reaction with Brucella spp.

Questionnaire data. A pretested and validated questionnaire was self-administered by participants in Arabic and information collected on demographic, environmental, and zoonotic risk factor information. The questionnaire was pretested by 40 individuals, and follow-up interviews were conducted with them to validate the instrument.

Ethics statement. The Institutional Research Bioethics Committee of JUST approved this study (Institutional Research Bioethics policy \# 7601). The bioethics committee of the Jordanian Ministry of Health also approved the study and granted permission to access the government health centers for sample collection. Signed informed consent from adult participants and parental consent for children were obtained before data and sample collection. All data were collected and stored confidentially and accessed only by the research team.

Statistical analyses. The $F$. tularensis seroprevalence status and demographic and risk factor information for each participant were entered into a Microsoft Excel sheet (Microsoft, Redmond, WA), which was then imported into Stata version 14.2 (StataCorp, College Station, TX) for analysis. Bivariate analyses were conducted to analyze the relationship between $F$. tularensis seropositivity and a number of demographic, zoonotic, and environmental variables, including ownership of various animals (cow, goat, sheep, camel, cats, and dogs). A final logistic regression was run to include variables found to be significant at a $P$-value $<0.05$ in the bivariate analysis and variables reported to be risk factors for F. tularensis seropositivity in the literature (gender). Results with $P<0.05$ were considered significant.

\section{RESULTS}

Of the 828 people included in the study, 64 (7.7\%) were seropositive for $F$. tularensis. The governorates with the highest seroprevalence were Irbid (15.2\%), Mafraq (14.9\%), and Balqa (11\%) (Figure 1). The lowest seroprevalence was reported in Ma'an (1.5\%) and Tafilah (2.7\%) (Figure 1).

The bivariate analyses showed that age, region, small ruminant ownership, and practicing horticulture were significantly associated with seropositivity (Tables 1 and 2). Significantly higher seroprevalence was found in those aged $\geq 50$ years $(10.5 \%)$ than those aged $\leq 30(5.4 \%)$ (Table 1$)$. Individuals living in the northern desert (Mafraq), northern highland (Ajloun, Irbid, and Jerash), and middle area (Amman, Zarqa, and Balqa) had

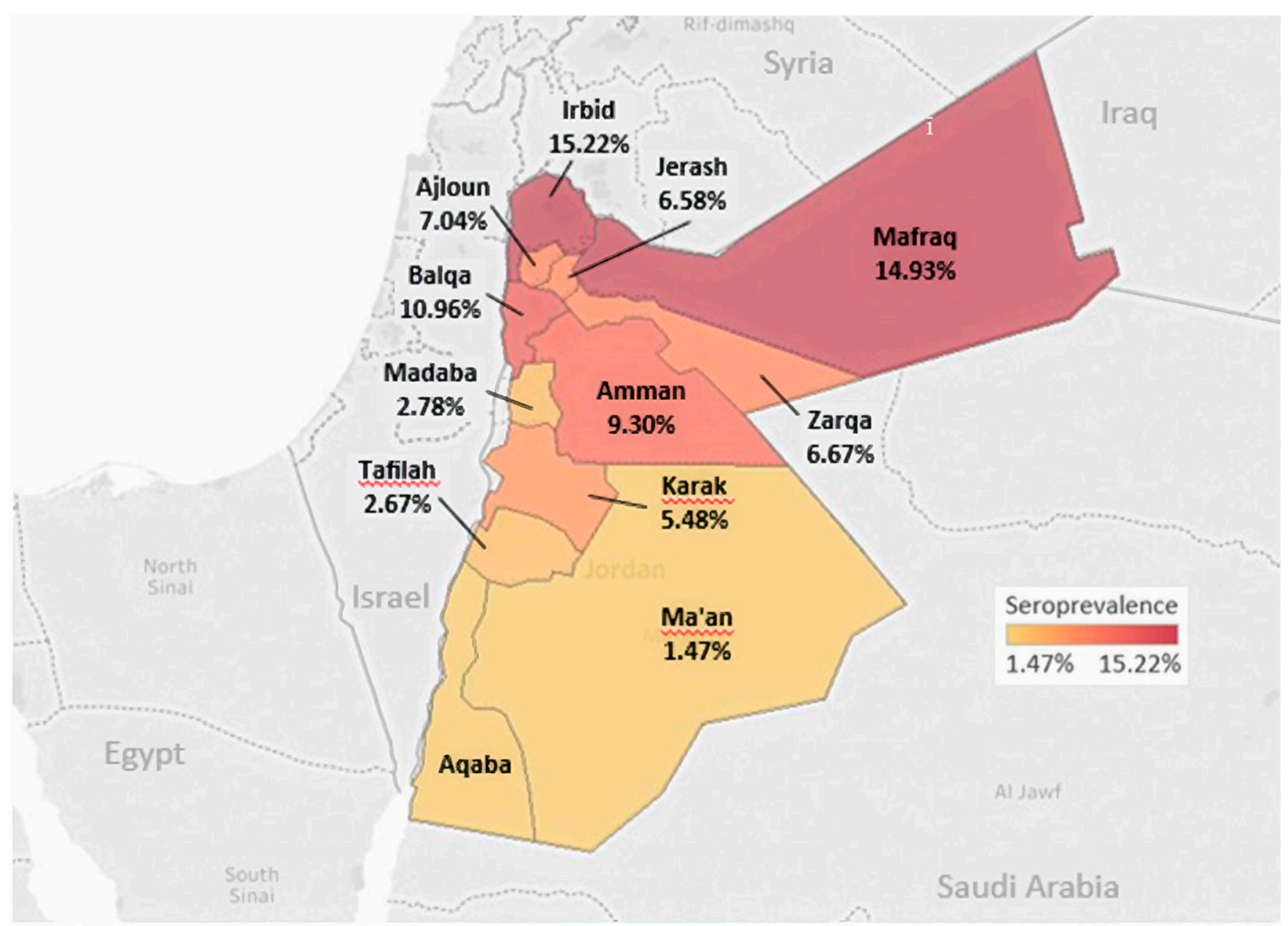

FIGURE 1. Spatial distribution of Francisella tularensis seropositivity in Jordan population, 2015-2016. This figure appears in color at www.ajtmh.org. 
TABLE 1

Descriptive statistics, seroprevalence, and unadjusted odds ratios for demographic variables associated with Francisella tularensis seropositivity in Jordan, 2015-2016 $(n=828)$

\begin{tabular}{|c|c|c|c|}
\hline Variable & $\begin{array}{c}\text { \# seropositive/\# tested } \\
\text { (\% seropositive) }\end{array}$ & Unadjusted OR & $P$-value \\
\hline \multicolumn{3}{|l|}{ Age (years) } & - \\
\hline$<30$ & $16 / 296(5.4 \%)$ & 1 & - \\
\hline $30-49$ & $24 / 304(7.9 \%)$ & $1.5(0.78-2.88)$ & 0.224 \\
\hline $50+$ & $24 / 228(10.5 \%)$ & $2.06(1.07-3.97)$ & 0.031 \\
\hline \multicolumn{4}{|l|}{ Gender } \\
\hline Male & $33 / 339(9.7 \%)$ & $1.59(0.96-2.66)$ & 0.074 \\
\hline Female & $31 / 489(6.3 \%)$ & 1 & - \\
\hline \multicolumn{4}{|l|}{ Region } \\
\hline Ňorthern desert (Mafraq) & 10/67 (14.9\%) & $5.24(1.91-14.37)$ & 0.001 \\
\hline Northern highland (Ajloun, Irbid, and Jerash) & $24 / 239(10.0 \%)$ & $3.33(1.41-7.90)$ & 0.006 \\
\hline Middle area (Amman, Zarqa, and Balqa) & $21 / 234(9 \%)$ & $2.94(1.22-7.07)$ & 0.016 \\
\hline Southern area (Karak, Tafilah, and Ma'an) & $7 / 216(3.2 \%)$ & 1 & - \\
\hline Dead Sea plateau (Madaba) & 2/72 (2.8\%) & $0.85(0.17-4.20)$ & 0.845 \\
\hline \multicolumn{4}{|l|}{ Education level } \\
\hline No education & $19 / 239(9 \%)$ & 1 & - \\
\hline Any education & $45 / 589(7.6 \%)$ & $0.96(0.55-1.67)$ & 0.880 \\
\hline \multicolumn{4}{|l|}{ Place of residence } \\
\hline Village or badia & $41 / 457(9 \%)$ & 1 & - \\
\hline City & $23 / 371(6.2 \%)$ & $0.67(0.39-1.14)$ & 0.140 \\
\hline \multicolumn{4}{|l|}{ Housing type } \\
\hline Apartment & $17 / 246(6.9 \%)$ & 1 & - \\
\hline House & $47 / 582(8.1 \%)$ & $1.18(0.66-2.10)$ & 0.567 \\
\hline \multicolumn{4}{|l|}{ Household income } \\
\hline More than 750 USD & $21 / 247(8.5 \%)$ & 1 & - \\
\hline Less than 750 USD & $43 / 581(7.4 \%)$ & $1.16(0.67-2.00)$ & 0.588 \\
\hline \multicolumn{4}{|l|}{ Did you live outside Jordan? } \\
\hline Yes & 9/126 (7.1\%) & $1.11(0.53-2.30)$ & 0.789 \\
\hline No & $55 / 702(7.8 \%)$ & 1 & - \\
\hline
\end{tabular}

significantly higher $(P<0.05)$ seroprevalence than individuals living in the southern area (Karak, Tafilah, and Ma'an) (Table 1). Individuals who own a small ruminant had significantly higher (12.6\%) seropositivity than those who do not own a small ruminant (6.4\%) (Table 2). Individuals who practice horticulture had significantly higher seropositivity $(13.8 \%)$ than individuals who do not practice horticulture (5.6\%) (Table 2).

There was no significant association between $F$. tularensis seropositivity and gender, education level, place of residence (village versus city), housing type (house versus apartment), and income level (Table 1). Ownership of cows, camels, dogs, and cats was not associated with seropositivity (Table 2). In addition, consumption of raw milk, undercooked meat, or wild traditional herbs and the source of drinking water were not associated with seropositivity (Table 2). Having a home backyard garden and growing vegetables in the backyard were also not associated with seropositivity (Table 2).

The final multivariate regression model included gender, age, region, small ruminant ownership, and practicing horticulture (Table 3 ). This analysis showed that region, small ruminant ownership, and practicing horticulture were significantly associated with $F$. tularensis seropositivity. Compared with individuals living in the southern area, individuals living in northern desert, middle area, and northern highland had greater odds of seropositivity 7.27 (95\% Cl: 2.49-21.19), 3.79 (95\% Cl: 1.53-9.39), and 3.52 (95\% Cl: 1.45-8.55), respectively. Individuals owning a small ruminant had 1.86 (95\% Cl: 1.02-3.40) higher odds for seropositivity than individuals who do not own a small ruminant. Individuals practicing horticulture had 2.10 (95\% Cl: $1.20-3.66)$ higher odds of seropositivity than individuals who do not practice horticulture (Table 3).

\section{DISCUSSION}

This study provides an insight into the seroprevalence of F. tularensis in Jordan and found that $7.7 \%$ of the study population was seropositive for $F$. tularensis. Lower seroprevalence was reported in endemic countries such as Germany ( $2 \%$ in hunters), ${ }^{15}$ Finland (2.0\%), ${ }^{16}$ Belgium (2.0\%), ${ }^{17}$ Turkey (0.3-2.1\%), ${ }^{18,19}$ and Austria (0.5\%), ${ }^{20}$ whereas higher seroprevalence was reported in the rural population in northern Azerbaijan (15.5\%) ${ }^{21}$ and in the western (14.4\%), ${ }^{22}$ southeastern (6.5\%), and southwestern (6\%) parts of Iran. ${ }^{11}$ These comparisons are somewhat limited because different tests were used. Nevertheless, these comparisons indicate varying regional differences that could be explained by varying exposures.

The bivariate and multivariate analyses show that region, small ruminant ownership, and practicing horticulture were significantly associated with seropositivity. Age was associated with seropositivity in the univariate but not the multivariate analyses. Other factors were not associated with seropositivity such as gender; education level; place of residence; housing type; income level; cows' and pets' ownership; consumption of raw milk, undercooked meat, and wild traditional herbs; and the source of drinking. In addition, having a home backyard garden was not associated with seropositivity.

The multivariate analysis showed that the seroprevalence in Jordan varies by region. Regional differences within the same country have been reported in Canada, ${ }^{23}$ Sweden, ${ }^{24,25}$ 
TABLE 2

Descriptive statistics, seroprevalence, unadjusted odds ratios for zoonotic and environmental factors with Francisella tularensis seropositivity in Jordan, 2015-2016 $(n=828)$

\begin{tabular}{|c|c|c|c|}
\hline Variable & $\begin{array}{c}\text { \# Positive/\# tested } \\
\text { (\% seropositive) }\end{array}$ & Unadjusted odds ratio & $P$-value \\
\hline \multicolumn{4}{|l|}{ Cow ownership } \\
\hline No & $56 / 755$ (7.4\%) & 1 & - \\
\hline Yes & $8 / 73(11 \%)$ & $1.54(0.70-3.36)$ & 0.283 \\
\hline \multicolumn{4}{|l|}{ Camel ownership } \\
\hline No & $63 / 815(7.7 \%)$ & 1 & - \\
\hline Yes & $1 / 13(7.7 \%)$ & $0.99(0.13-7.74)$ & 0.996 \\
\hline \multicolumn{4}{|l|}{ Small ruminant ownership } \\
\hline No & $41 / 646(6.4 \%)$ & 1 & - \\
\hline Yes & $23 / 182(12.6 \%)$ & $2.13(1.24-3.66)$ & 0.006 \\
\hline \multicolumn{4}{|l|}{ Cat ownership } \\
\hline No & $58 / 777(7.5 \%)$ & 1 & - \\
\hline Yes & $6 / 51(11.8 \%)$ & $1.65(0.68-4.04)$ & 0.270 \\
\hline \multicolumn{4}{|l|}{ Dog ownership } \\
\hline No & $53 / 739(7.2 \%)$ & 1 & - \\
\hline Yes & $11 / 89(12.4 \%)$ & $1.83(0.92-3.64)$ & 0.088 \\
\hline \multicolumn{4}{|l|}{ Drinks raw milk } \\
\hline No & $53 / 738$ (7.2\%) & 1 & - \\
\hline Yes & $11 / 90(2.2 \%)$ & $1.80(0.90-3.59)$ & 0.095 \\
\hline \multicolumn{4}{|l|}{ Eats undercooked meat } \\
\hline No & $56 / 757(7.4 \%)$ & 1 & - \\
\hline Yes & 8/71 (11.3\%) & $1.59(0.73-3.48)$ & 0.247 \\
\hline \multicolumn{4}{|l|}{ Eats traditional wild herbs } \\
\hline No & $31 / 372(8.3 \%)$ & 1 & - \\
\hline Yes & $33 / 456$ (7.2\%) & $0.86(0.52-1.43)$ & 0.557 \\
\hline \multicolumn{4}{|l|}{ Source of drinking water* } \\
\hline Rain collection cistern & 10/87 (11.5\%) & $1.65(0.81-3.38)$ & 0.168 \\
\hline Filtered water & $42 / 524(8.02=\%)$ & $1.12(0.65-1.91)$ & 0.686 \\
\hline Municipality water & $17 / 249(6.83=\%)$ & $0.83(0.47-1.48)$ & 0.524 \\
\hline Spring lakes & $5 / 49(10.2 \%)$ & $1.39(0.53-3.63)$ & 0.504 \\
\hline \multicolumn{4}{|l|}{ Has a backyard garden } \\
\hline No & $41 / 518(7.9 \%)$ & 1 & - \\
\hline Yes & $23 / 310(7.4 \%)$ & $0.93(0.55-1.59)$ & 0.796 \\
\hline \multicolumn{4}{|c|}{ Grows vegetables in the backyard } \\
\hline No & $46 / 609$ (7.6\%) & 1 & - \\
\hline Yes & $18 / 219(8.2 \%)$ & $1.10(0.620-1.93)$ & 0.752 \\
\hline \multicolumn{4}{|l|}{ Practices horticulture } \\
\hline No & $34 / 610(5.6 \%)$ & 1 & - \\
\hline Yes & $30 / 218(13.8 \%)$ & $2.70(1.61-4.54)$ & 0.000 \\
\hline
\end{tabular}

* Water sources were not mutually exclusive; some respondents named 2 water sources.

Azerbaijan, ${ }^{21}$ and Iran. ${ }^{11}$ These difference might be attributed to differences in tick density by region, annual rainfall, and presence of $F$. tularensis reservoirs.

The multivariate analysis showed that individuals who own a small ruminant have 1.86 higher odds of seropositivity than those who do not own a small ruminant. This might be attributed to the possibility that small ruminants can get infected with $F$. tularensis. For example, $F$. tularensis was confirmed as a cause of abortions in sheep in the Unites States. ${ }^{26}$ In addition, goats in northwest Tuscany (Italy) and sheep in Bulgaria and Turkey $^{27}$ tested positive for $F$. tularensis. ${ }^{28}$ Moreover, cases of tularemia transmitted from sheep to humans were reported in Turkey. ${ }^{29}$

Individuals practicing horticulture in Jordan had 2.1 higher odds for seropositivity than individuals who do not practice horticulture, and this is in line with previous reports. For example, a $4.0 \%$ seroprevalence of anti-F. tularensis IgG was reported in employees of forestry enterprises in Germany ${ }^{30}$

TABLE 3

Final multivariate logistic regression model of Francisella tularensis seropositivity in Jordan population, 2015-2016

\begin{tabular}{|c|c|c|c|}
\hline Variable & Adjusted odds ratio & $P$-value & $95 \% \mathrm{Cl}$ \\
\hline Age $\left(30-49\right.$ years) ${ }^{*}$ & 1.63 & 0.158 & $0.83-3.21$ \\
\hline Age $(50+\text { years })^{*}$ & 1.77 & 0.112 & $0.88-3.58$ \\
\hline Male† & 1.55 & 0.125 & $0.88-2.73$ \\
\hline Northern desert (Mafraq) $\ddagger$ & 7.27 & 0.000 & $2.49-21.19$ \\
\hline Northern highland (Ajloun, Irbid, and Jerash) $\ddagger$ & 3.52 & 0.006 & $1.45-8.55$ \\
\hline Middle area (Amman, Zarga, and Balqa) $\ddagger$ & 3.79 & 0.004 & $1.53-9.39$ \\
\hline Dead Sea plateau (Madaba) $\ddagger$ & 1.09 & 0.921 & $0.21-5.48$ \\
\hline Own a small ruminant (yes) & 1.86 & 0.042 & $1.02-3.40$ \\
\hline Practices horticulture (yes) & 2.10 & 0.000 & $1.20-3.66$ \\
\hline
\end{tabular}

Practices horticulture (yes)

"Compared with reference age-group ( $<30$ years).

†Compared with female.

$\ddagger$ Compared with southern areas (Karak, Tafilah, and Ma'an). 
and among individuals in Finland participating in farming activities (land preparation, cleaning barns, producing silage, and harvesting hay). ${ }^{31}$

Several factors that are associated with $F$. tularensis in the literature were not associated with seropositivity in this study including age, source of drinking water, and contact with cats. For example, age was associated with seropositivity in Canada ${ }^{23}$ and Iran. ${ }^{22}$ Water was also confirmed as a source of human tularemia in Turkey, ${ }^{8,32}$ but there was no association between water source and seropositivity in ours, and this may be due to the nearly ubiquitous access to treated water in Jordan. In addition, contact with cats was linked to several tularemia cases in the United States. ${ }^{33,34}$ In Jordan, few households have cats that live in the home. The seroprevalence did not differ between males and females in our study, which is in line with previous reports from Canada $^{23}$ and Iran. ${ }^{22}$

This cross-sectional study provided solid initial evidence of $F$. tularensis and its risk factors in Jordan and established an association between seropositivity and small ruminant ownership and practicing horticulture. The nonspecific signs of tularemia including fever and lymphadenopathy might make the diagnosis difficult for general practitioners and can contribute to underreporting. Thus, it is recommended that clinicians consider tularemia as a differential diagnosis for patients presenting with lymphadenopathies and inflammatory neck masses, especially those who are in contact with small ruminants. Further research is needed to identify clinical cases of tularemia in Jordan and to determine the circulating $F$. tularensis subspecies.

Received April 30, 2019. Accepted for publication May 8, 2020.

Published online June 8, 2020.

Acknowledgments: We thank the study participants and healthcare professionals for their help.

Financial support: The study was financially supported by the Cooperative Biological Engagement Program of the U.S. Defense Threat Reduction Agency and Georgian Research and Development Foundation (GRDF) under research project \# A-61053.

Authors' addresses: Mohammad M. Obaidat and Alaa E. Bani Salman, Department of Veterinary Pathology and Public Health, Faculty of Veterinary Medicine, Jordan University of Science and Technology, Irbid, Jordan, E-mails: mmobaidat@just.edu.jo and aebanisalman@ just.edu.jo. Lile Malania, National Center for Disease Control and Public Health, Tbilisi, GA, E-mail: malanial@yahoo.com. Ryan J. Arner, Ryan Arner Science Consulting, LLC, Freeport, PA, E-mail: ryan.j.arner@gmail.com. Amira A. Roess, Department of Global and Community Health, College of Health and Human Services, George Mason University, Fairfax, VA, E-mail: aroess@gmu.edu.

\section{REFERENCES}

1. McLendon MK, Apicella MA, Allen LH, 2006. Francisella tularensis: taxonomy, genetics, and immunopathogenesis of a potential agent of biowarfare. Annu Rev Microbiol 60: 167-185.

2. Hestvik G et al., 2014. The status of tularemia in Europe in a onehealth context: a review. Epidemiol Infect 143: 2137-2160.

3. Petersen JM, Mead PS, Schriefer ME, 2009. Francisella tularensis: an arthropod-borne pathogen. Vet Res 40: 7.

4. Stromdahl EY, Hickling GJ, 2012. Beyond Lyme: aetiology of tickborne human diseases with emphasis on the south-eastern United States. Zoonoses Public Health 59: 48-64.

5. Feldman KA, 2003. Tularemia. J Am Vet Med Assoc 222: 725-730.

6. Weber IB, Turabelidze G, Patrick S, Griffith KS, Kugeler KJ, Mead $P S, 2012$. Clinical recognition and management of tularemia in Missouri: a retrospective records review of 121 cases. Clin Infect Dis 55: 1283-1290.
7. Akhvlediani $\mathrm{N}$ et al., 2018. Tularemia transmission to humans: a multifaceted surveillance approach. Epidemiol Infect 146: 2139-2145.

8. Aktas D, Celebi B, Isik ME, Tutus C, Ozturk H, Temel F, Kizilaslan $\mathrm{M}$, Zhu BP, 2015. Oropharyngeal tularemia outbreak associated with drinking contaminated tap water, Turkey, 2013. Emerg Infect Dis 21: 2194-2196.

9. Nakamura K, Fujita H, Miura T, Igata Y, Narita M, Monma N, Hara Y, Saito K, Matsumoto A, Kanemitsu K, 2018. A case of typhoidal tularemia in a male Japanese farmer. Int $J$ Infect Dis 71: 56-58.

10. Wang $Y$ et al., 2014. Diversity of Francisella tularensis subsp. holarctica lineages, China. Emerg Infect Dis 20: 1191-1194.

11. Zargar A, Maurin M, Mostafavi E, 2015. Tularemia, a re-emerging infectious disease in Iran and neighboring countries. Epidemiol Health 37: e2015011.

12. Njeru J, Tomaso H, Mertens K, Henning K, Wareth G, Heller R, Kariuki S, Fevre EM, Neubauer H, Pletz MW, 2017. Serological evidence of Francisella tularensis in febrile patients seeking treatment at remote hospitals, northeastern Kenya, 2014-2015. New Microbes New Infect 19: 62-66.

13. World Bank, 2018. Jordan: Data. Available at: https://data. worldbank.org/country/jordan. Accessed May 20, 2018.

14. Chaignat V, Djordjevic-Spasic M, Ruettger A, Otto P, Klimpel D, Müller W, Sachse K, Araj G, Diller R, Tomaso H, 2014. Performance of seven serological assays for diagnosing tularemia. $B M C$ Infect Dis 14: 234.

15. Jenzora A, Jansen A, Ranisch H, Lierz M, Wichmann O, Grunow $\mathrm{R}$, 2008. Seroprevalence study of Francisella tularensis among hunters in Germany. FEMS Immunol Med Microbiol 53: 183-189.

16. Rossow H, Ollgren J, Hytonen J, Rissanen $\mathrm{H}$, Huitu $\mathrm{O}$, Henttonen $\mathrm{H}$, Kuusi M, Vapalahti O, 2015. Incidence and seroprevalence of tularaemia in Finland, 1995 to 2013: regional epidemics with cyclic pattern. Euro Surveill 20: 21209.

17. De Keukeleire M, Vanwambeke SO, Cochez C, Heyman P, Fretin D, Deneys V, Luyasu V, Kabamba B, Robert A, 2017. Seroprevalence of Borrelia burgdorferi, Anaplasma phagocytophilum, and Francisella tularensis infections in Belgium: results of three population-based samples. Vector Borne Zoonotic Dis 17: 108-115.

18. Dedeoglu Kilinc G, Gurcan S, Eskiocak M, Kilic H, Kunduracilar H, 2007. Investigation of tularemia seroprevalence in the rural area of Thrace region in Turkey. Mikrobiyol Bul 41: 411-418.

19. Yazgi H, Uyanik MH, Ertek M, Kilic S, Kirecci E, Ozden K, Ayyildiz $A, 2011$. Tularemia seroprevalence in the risky population living in both rural and urban areas of Erzurum. Mikrobiyol Bul 45: 67-74.

20. Tobudic S, Nedomansky K, Poeppl W, Müller M, Faas A, Mooseder G, Allerberger F, Stanek G, Burgmann H, 2014. Seroprevalence for Coxiella burnetii, Francisella tularensis, Brucella abortus and Brucella melitensis in Austrian adults: a cross-sectional survey among military personnel and civilians. Ticks Tick Borne Dis 5: 315-317.

21. Clark DV et al., 2012. Seroprevalence of tularemia in rural Azerbaijan. Vector Borne Zoonotic Dis 12: 558-563.

22. Esmaeili S, Gooya MM, Shirzadi MR, Esfandiari B, Amiri FB, Behzadi MY, Banafshi O, Mostafavi E, 2014. Seroepidemiological survey of tularemia among different groups in western Iran. Int J Infect Dis 18: 27-31.

23. Messier V, Lévesque B, Proulx J-F, Rochette L, Serhir B, Couillard M, Ward BJ, Libman MD, Dewailly É, Déry S, 2012. Seroprevalence of seven zoonotic infections in Nunavik, Quebec (Canada). Zoonoses Public Health 59: 107-117.

24. Desvars A, Furberg M, Hjertqvist M, Vidman L, Sjostedt A, Ryden $P$, Johansson A, 2015. Epidemiology and ecology of tularemia in Sweden, 1984-2012. Emerg Infect Dis 21: 32-39.

25. Desvars-Larrive A, Liu X, Hjertqvist M, Sjostedt A, Johansson A, Ryden $P, 2017$. High-risk regions and outbreak modelling of tularemia in humans. Epidemiol Infect 145: 482-490.

26. O'Toole D, Williams ES, Woods LW, Mills K, Boerger-Fields A, Montgomery DL, Jaeger $\mathrm{P}$, Edwards $\mathrm{WH}$, Christensen $\mathrm{D}$, Marlatt W, 2008. Tularemia in range sheep: an overlooked syndrome? J Vet Diagn Invest 20: 508-513. 
27. Korudgiyski N, Bonovska M, llieva D, lliev E, 2004. Serological investigations on the distribution of tularemia in animals in risk regions of Bulgaria. Zhivotnov'dni Nauki 41: 63-64.

28. Corrias $F$ et al., 2012. Health evaluation in the native Garfagnina goat. Small Rum Res 104: 191-194.

29. Senol M, Ozcan A, Karincaoglu Y, Aydin A, Ozerol IH, 1999. Tularemia: a case transmitted from a sheep. Cutis 63: 49-51.

30. Jurke A et al., 2015. Serological survey of Bartonella spp., Borrelia burgdorferi, Brucella spp., Coxiella burnetii, Francisella tularensis, Leptospira spp., Echinococcus, Hanta-, TBE- and XMRvirus infection in employees of two forestry enterprises in North Rhine-Westphalia, Germany, 2011-2013. Int J Med Microbiol 305: 652-662.
31. Rossow H, Ollgren J, Klemets P, Pietarinen I, Saikku J, Pekkanen E, Nikkari S, Syrjälä H, Kuusi M, Nuorti JP, 2013. Risk factors for pneumonic and ulceroglandular tularaemia in Finland: a population-based case-control study. Epidemiol Infect 142: 2207-2216.

32. Kilic $S$ et al., 2015. Water as source of Francisella tularensis infection in humans, Turkey. Emerg Infect Dis 21: 2213-2216.

33. Larson MA, Fey PD, Hinrichs SH, Iwen PC, 2014. Francisella tularensis bacteria associated with feline tularemia in the United States. Emerg Infect Dis 20: 2068-2071.

34. Stidham RA, Freeman DB, von Tersch RL, Sullivan PJ, Tostenson SD, 2018. Epidemiological review of Francisella: a case study in the complications of dual diagnoses. PLoS Curr 10: ecurrents.outbreaks.8eb0b55f377abc2d250314bbb8fc9d6d. 